\title{
Residential Electricity Tariffs in Europe: Current Situation, Evolution and Impact on Residential Flexibility Markets ${ }^{\dagger}$
}

\author{
Youssef Oualmakran ${ }^{1}$, Juan Manuel Espeche ${ }^{2, *}$, Mario Sisinni ${ }^{2}$, Thomas Messervey ${ }^{2}$ and \\ Zia Lennard ${ }^{2}$ \\ 1 Laborelec, Rodestraat 125, 1630 Linkebeek, Belgium; youssef.oualmakran@external.engie.com \\ 2 R2M Solution, s.r.l., Via Fratelli Cuzio 42, Pavia 27100, Italy; mario.sisinni@r2msolution.com (M.S.); \\ thomas.messervey@r2msolution.com (T.M.); zia.lennard@r2msolution.com (Z.L.) \\ * Correspondence: juan.espeche@r2msolution.com; Tel.:+39-382-172-6596 \\ † Presented at the Sustainable Places 2017 (SP2017) Conference, Middlesbrough, UK, 28-30 June 2017.
}

Published: 9 November 2017

\begin{abstract}
Residential flexibility (a.k.a demand response) is a key component of smart grids to reduce our carbon footprint, to have reliable power (balance between power and demand, and avoiding congestion) and more affordable electricity tariffs. However, to have a significant participation in the flexibility markets, households needs good price signals. Today, the electricity bill components (volumetric and capacity for both consumption and generation) are evolving and grid services are increasingly more available to households. This is due to the evolution in the energy mix, deployment of new technologies (smart meter roll-out, gradual uptake of electric vehicles, heat pumps and batteries), regional integration (interconnectors and integration of balancing markets) and evolution of society (sharing economy or Peer2peer and ubiquity of smartphones). These trends will have a quantitative impact on the different energy bills in the short term (2020) and longer term. Further investigation is also suggested to go from the qualitative analysis to a better quantitative analysis.
\end{abstract}

Keywords: tariffs; demand response; residential; distributed energy resources (DER); Mas²tering project

\section{Introduction}

Tariffs as studied in the Mas²tering (Multi-Agent Systems and Secured coupling of Telecom and Energy gRIds for Next Generation smart grid services) project, must correctly balance a complex set of interests in the electrical grid. Suppliers generating electricity must be fairly compensated for energy produced, distributors who are typically regulated must be fairly compensated for the service they provide and to have adequate funds for the maintenance and expansion where necessary of the distribution grid, and consumers/prosumers should have access to the grid in a fair way for both consumption and production. For this reason, electricity tariffs are composed of various components which seek to fairly balance these aspects. Changes in policy, increased urbanization, increased electrification, the increased penetration of renewable energy technologies and the increased availability of smart technologies have an impact on the different tariff components. As a result, residential domestic bills are changing very quickly across the European Union (EU). For example, tariffs favouring residential photovoltaics (PV) self-consumption are becoming more widespread (e.g., in Belgium, in Flanders implemented it recently and similar regulations under discussion to be implemented in Wallonia by 2019). More pressures for changes are coming from instances such as the European Commission (e.g., the so-called Winter Package announced in November 2016 and 
earlier advanced metering infrastructure deployments) and Distribution System/Network Operators (e.g., Eurelectric papers) [1-5].

\section{Drivers for Electricity Tariffs Evolution}

The bills in 2025 and 2035 will probably look different than today. Here are the different factors having an impact on how the four components are billed (time, location) and how much they are billed. The two inherent factors are a physical constraint (balancing needs) and an engineering limit (avoidance of congestions):

- Balancing needs: In the electricity grid at every moment supply (generation) and consumption must be the same with possible contributions from batteries and other storage systems (that can act either as generation when batteries are discharged or as consumption when they are charged) and import/export from outside the considered grid (the exterior grid is the transmission grid for a distribution grid, and interconnectors for the transmission grid). For the sake of simplicity, we have not included the losses (they represent typically about 3\% in European urban distribution grids).

- Congestion avoidance: Power networks are made of overhead lines, underground cable, transformers, etc. These components can only sustain a given level of current/voltage otherwise they will not work properly or even be damaged. This limit is due to the engineering limits of the component: too much current generates heat and too much voltage cause problem at the insulation level.

The evolution of the grid in the broader sense (i.e., including regulatory) can either have a positive or a negative impact on balancing and congestion. The different drivers for the evolution of the grid are:

- Energy mix evolution: PV and wind installed capacity is expected to increase. The effect can be very different on the balancing and congestion constraints. A small level of PV spread over a large area has a positive peak shaving effect, since at noon when the irradiation, and hence the PV generation, has its peak corresponds typically to the peak energy demand and maximum flow on the grid. However large penetration of PV without a smart configuration would lead to overproduction at noon causing local overvoltage problems and congestion on the local lines. Curtailing generation is possible but would lead to economic losses. The growth of storage systems (mainly batteries) would reduce the imbalances between production and consumption and the constraints on the distribution network.

- Evolution of the grid: More interconnections with neighboring countries would enable a country with undersupply to get energy from a country with oversupply which will reduce the imbalances and the difference between peak and off-peak volumetric consumption prices.

- Regulatory changes: Changes regarding all bill components are possible such as for example inclusion of a volumetric feed-in tariff or volumetric time of use. Access to grid services such as frequency regulation for residential users could be possible through aggregators.

- Smart meter roll-outs: Some EU countries have already deployed smart meters (Finland, Italy, Malta, Sweden), other are expected to have at least 80\% deployment by 2020 (Austria, Denmark, Estonia, France, Greece, Ireland, Luxembourg, the Netherlands, Spain, Slovakia, UK), while other will have limited deployment (e.g., Germany).

- Societal changes: The sharing economy is becoming increasingly more popular and has led to the concept of local energy communities or peer-to-peer local energy platform. They are suggested by the EU Winter Packaged and new regulation in France is under discussion to make it easier for local energy exchange. With the improvement in battery technology and cost, more and more EVs are sold. Heat pumps are also receiving more interest as domestic batteries. 


\section{Likelihood of Different Evolutions}

Some evolutions are more likely than other. For example, the authors expect that selfconsumption tariffs for PV would become common in countries with high PV penetration (say when over $3-5 \%$ of annual consumption comes from solar power). Smart meters deployment is compulsory by regulators in some countries and the evolution is good. Table 1 summarizes the potential evolutions of the grid and the expected likelihood.

Table 1. Likelihood of tariffs evolving under various distributed energy resources (DER) technologies.

\begin{tabular}{|c|c|}
\hline Concept & Likelihood \\
\hline Self-consumption tariffs for PV & High in markets with PV penetration $>3 \%$ national consumption \\
\hline Smart meters & High. Under progression \\
\hline $\begin{array}{l}\text { EV penetration with demand } \\
\text { response }\end{array}$ & \multirow{5}{*}{ High/Low High if tariffs are favorable otherwise low. } \\
\hline $\begin{array}{l}\text { EV penetration without demand } \\
\text { response }\end{array}$ & \\
\hline Heat pump with demand response & \\
\hline $\begin{array}{l}\text { Heat pump without demand } \\
\text { response }\end{array}$ & \\
\hline Storage penetration & \\
\hline Volumetric time of use & $\begin{array}{l}\text { Medium. Smart meters deployment make them technically relatively easy to } \\
\text { implement }\end{array}$ \\
\hline $\begin{array}{l}\text { Dynamic capacity tariff for } \\
\text { consumption }\end{array}$ & Low. Requires locational tariff and monitoring at low voltage level. \\
\hline $\mathrm{P} 2 \mathrm{P}$ & Low. Requires shift in philosophy/economic system. \\
\hline PV penetration & Medium. Depends on retail price and PV price. \\
\hline Wind penetration & $\begin{array}{l}\text { Medium. Depends on policy regarding energy mix (e.g., subsidy, carbon price, etc.) } \\
\text { and technology price. }\end{array}$ \\
\hline Interconnectors capacity & Medium/high. Already under construction/planning \\
\hline
\end{tabular}

\section{Grid Balancing to Alleviate Congestion}

Pursuing balancing goals through demand response, means that demand should follow closely the generation profile that looks like a bell curve or like a sawtooth wave when intermittent sources (wind and PV) are largely present. On the other hand to reduce the investments due to congestion issues the curve has to be flat. Therefore, the probability of facing conflict scenarios is real and will represent a challenge for grid; for example if a large city such as Brussels that have low renewable potential import intermittent energy from far away (e.g., a large wind park and/or large PV park). If the balancing incentives dominates, then citizen would have a peak in demand when they are abundant (e.g., round noon in the case of PV) causing possible congestion problems. There are also other differences between balancing and congestion worth to be noted:

- Balancing can be done at a national level or even continental level if the interconnectors are present. But congestion deals with local limits of cables, lines, transformers and has to be local. Balancing markets can thus have a larger customer base (national or even cross-country level, see from example Epex Spot Stock Exchange) while congestion markets are limited to small areas such as cities or even neighborhood. Not surprising that balancing markets are already mature (at least for large customers/aggregators) while congestion markets are still at the concept study.

- The different evolution may lead to stranded assets for Distribution and Transmission System Operators and central energy producers.

\section{Examples of Tariffs for Residential Demand Response (DR)}

In France, a combination of Capacity Peak Pricing (CPP) and Time of Use (TOU) pricing is applicable for customers that apply for the "Tempo Tariff". Sweden tested a tariff for network congestions. The clients receive a demand-based time-of-use electricity distribution tariff. The demand-based tariff consists of the fixed access charge (SEK/yr.) and a variable distribution charge 
$(\mathrm{SEK} / \mathrm{kW})$ that is calculated based on the average of the five highest hourly meter readings during peak hours. In off-peak hours, electricity distribution is free of charge. This results in: Peak demand reduction between $7.5 \%$ and $9.3 \%$; The total shift from peak to off-peak hours was between $2.4 \mathrm{~h}$ and $0.2 \mathrm{~h}$; and individual households saw a decrease from $14 \%$ to $41 \%$ in costs.

\section{Challenges for the Evolution of DR Tariffs}

Four categories can exemplify the key challenges of demand response tariffs, listed and briefly summarized as follows:

\section{Initial technology investments}

- Installation of smart meters, in-home displays, and other devices for enabling DR is costly

- Without any clear business model for investments, no actor will make the first move

\section{Coordination problems}

- Actors involved in electricity supply could require the demand to be adjusted downward, while others could actually require upward demand adjustments.

\section{Flexibility and traditional markets}

- New rules for balancing, ancillary, and real-time trading should be adjusted to accommodate aggregated load flexibility.

- Need for a compensation mechanism that guarantees that electricity suppliers are not penalized for imbalances caused by activities of (independent) aggregators

Side-effects of DR: shifting peaks and increasing emissions

- A relevant issue with DR tariff schemes is that instead of peak reduction and valley filling, a shifted peak is frequently observed.

\section{Conclusions}

Residential flexibility requires electrical bills giving incentives to shift demand. This paper explains on one hand the bill components for residential customers and their importance for flexibility and the other hand the trends in their evolution are highlighted. A combined description of both aspects is seldom found in the literature. This article helps to understand the current and future potential of residential flexibility. Further analysis can be done by using available data (e.g., wholesale prices to refine volumetric time of use), but other are more difficult to get (e.g., grid congestion at the distribution level, sometimes they are even not monitored). Some final comments to summarize the state of the art of the residential electricity tariffs and its impact in the flexibility market:

- Currently no urgency for demand response from the residential sector due to overcapacity in the distribution grid and therefore the evolution of promoting tariffs is moving slow

- In a liberalized electricity sector, taxes, network charges, and retail charges are separately defined and this affect price clarity for the end-user

- New rules for balancing, ancillary, and real-time trading should be adjusted to accommodate aggregated load flexibility.

- Clear business models are needed to reduce the risk of grid operators or new players of making the first step towards the creation of a residential flexibility market.

Acknowledgments: Mas²tering (Multi-Agent Systems and Secured coupling of Telecom and Energy gRIds for Next Generation smart grid services) is co-funded by the European Union under the FP7 programme, grant $n^{\circ}$ 619682. The Mas²tering project can be referenced at http://www.mas2tering.eu/.

Author Contributions: Sections written by Youssef Oualmakran, Juan Manuel Espeche, Mario Sisinni, and Thomas Messervey. Paper compiled, edited, and reviewed by Zia Lennard. 
Conflicts of Interest: The authors declare no conflict of interest.

\section{References}

1. European Commission. Commission Proposes New Rules For Consumer Centred Clean Energy Transition. Available online: https:/ec.europa.eu/energy/en/news/commission-proposes-new-rules-consumercentred-clean-energy-transition (accessed on 30 November 2016).

2. European Commission. New Electricity Market Design: A Fair Deal for Consumers. Available online: https:/ec.europa.eu/energy/sites/ener/files/documents/technical_memo_marketsconsumers.pdf (accessed on 30 November 2016).

3. Eurelectric. Netwok Tarifs: A Eurelectric Position Paper. Available online: http://www.eurelectric.org/media/268408/network_tariffs_position_paper_final_as-2016-030-0149-01e.pdf (accessed on 2 March 2016).

4. Eurelectrc. Retail Pricing For a Cost-Effective Transition to a Low Carbon Power System. Available online: http://www.eurelectric.org/media/282159/retail_pricing_for_a_cost-effective_transition-lr-2016-2500-000801-e.pdf (accessed on 15 June 2016).

5. European Commission, Joint Research Center. Smart Metering Deployment in the European Union. Available online: http://ses.jrc.ec.europa.eu/smart-metering-deployment-european-union (accessed on 15 May 2017).

(C) 2017 by the authors. Licensee MDPI, Basel, Switzerland. This article is an open access article distributed under the terms and conditions of the Creative Commons Attribution (CC BY) license (http://creativecommons.org/licenses/by/4.0/). 